\title{
Meta-analysis of percutaneous radiofrequency ablation versus ethanol injection in hepatocellular carcinoma
} Carmen Bouza*, Teresa López-Cuadrado, Raimundo Alcázar, Zuleika SazParkinson and José María Amate

Address: Healthcare Technology Assessment Agency, Carlos III Health Institute, Madrid, Spain

Email: Carmen Bouza* - cbouza@isciii.es; Teresa López-Cuadrado - teresalc@isciii.es; Raimundo Alcázar - ralcazar@isciii.es; Zuleika SazParkinson-zuleika@isciii.es; José María Amate - jamate@isciii.es

* Corresponding author

Published: II May 2009

BMC Gastroenterology 2009, 9:3| doi:|0.||86/|47|-230X-9-3|
Received: 15 December 2008

Accepted: II May 2009

This article is available from: http://www.biomedcentral.com/I47I-230X/9/3।

(C) 2009 Bouza et al; licensee BioMed Central Ltd.

This is an Open Access article distributed under the terms of the Creative Commons Attribution License (http://creativecommons.org/licenses/by/2.0), which permits unrestricted use, distribution, and reproduction in any medium, provided the original work is properly cited.

\begin{abstract}
Background: Percutaneous radiofrequency ablation (RFA) has gained popularity in the treatment of hepatocellular carcinoma (HCC). However, its role versus other conventional minimally invasive therapies is still a matter of debate. The purpose of this work is to analyse the efficacy and safety of RFA versus that of ethanol injection (PEI), the percutaneous standard approach to treat nonsurgical HCC.
\end{abstract}

Methods: Systematic review and meta-analysis of randomised or quasi-randomised controlled trials published up to August 2008 in PubMed, ISI Web of Science and The Cochrane Library. Overall survival, local recurrence rate and adverse effects were considered as primary outcomes. Studies were critically appraised and estimates of effect were calculated according to the randomeffects model. Inconsistency across studies was evaluated using the $\mathrm{I}^{2}$ statistic. Sensitivity analyses were conducted to explore statistical heterogeneity.

Results: Six studies were eligible. The studies reported data on 396 patients treated by RFA and $39 \mathrm{I}$ treated by PEI. In general, subjects were in Child-Pugh class A (74\%) and had unresectable HCC (mean size $2.5 \mathrm{~cm}$ ). Mean follow-up was $25 \pm$ II months. The survival rate showed a significant benefit for RFA over PEl at one, two, three and four years. The advantage in survival increased with time with Relative Risk values of: 1.28 (95\%Cl:1.12-1.45) and I.24 (95\%Cl:1.05-1.48) for RFA versus PEI at 3- and 4-years respectively. Likewise, RFA achieved significantly lower rates of local recurrence (RR: $0.37,95 \% \mathrm{Cl}: 0.23-0.59$ ). The overall rate of adverse events was higher with RFA (RR:2.55, 95\%Cl: I.8-3.6) yet no significant differences were found concerning major complications (RR:I.85, 95\%Cl: 0.68-5.0I). There was not enough evidence supporting a better cost-effectiveness ratio for RFA compared to PEl.

Conclusion: Available evidence from adequate quality controlled studies support the superiority of RFA versus PEI, in terms of better survival and local control of the disease, for the treatment of patients with relatively preserved liver function and early-stage non-surgical HCC. However, the higher rate of adverse events displayed is something that will have to be tested with appropriate weighting of the possible benefits in each individual case. Overall cost-effectiveness of RFA needs further evaluation. 


\section{Background}

Worldwide, hepatocellular carcinoma (HCC) constitutes an important problem for healthcare systems due to its high morbidity, mortality and progressive incidence [1]. HCC is the sixth leading tumour in the world [2], and it is estimated that its incidence will continue to rise in coming decades $[3,4]$. It is an aggressive tumour that usually develops in a cirrhotic liver with limited functional reserve, and without treatment registers a short survival after diagnosis [5]. Furthermore, unlike other tumours, HCC can be offered few possibilities of curative radical treatment [1]. Indeed, despite the fact that screening systems have improved the early diagnosis rate [6], the vast majority of patients are not susceptible to curative treatment when this tumour is detected [7].

Over the past few years, several methods for percutaneous tumour destruction have been developed [8,9]. Out of these, radiofrequency ablation (RFA) is the one that has attracted greatest interest and popularity and, presently, it is the most widely employed liver-directed treatment of early-stage non-surgical HCC $[10,11]$. Indeed, there has been a drastic shift from standard percutaneous treatments, such as Percutaneous Ethanol Injection (PEI), to RFA since the introduction of the latter in clinical practice [12].

Yet, to date, little is known of the efficacy and safety of percutaneous RFA versus that of other conventional minimally invasive loco-regional therapies [12-15], and the advantages of RFA versus PEI in terms of cardinal outcomes, such as survival, have not been demonstrated $[1,13,14]$.

Accordingly, based on a systematic review and meta-analysis of the literature, this study sought to assess existing evidence about the efficacy and safety of percutaneous RFA versus that of PEI in the management of HCC.

\section{Methods}

A review of the literature was conducted in PubMed, ISI Web of Science and The Cochrane Library from January 1990 to August 2008, using the following terms: "carcinoma, hepatocellular" [MeSH Terms], "radiofrequency catheter ablation" [MeSH Terms], "ethanol injection" [Text Word] and "controlled trial" [Publication Type]. Similarly, a manual search of the relevant references was made and experts were contacted in order to identify published studies [15]. Conversely, we did not attempt to contact companies producing RFA equipment.

\section{Inclusion criteria}

Sackett's criteria [16], duly amended, were applied as follows: 1) population: randomised or quasi-randomised controlled studies conducted on more than 10 adults with formal diagnosis of HCC; 2) intervention: percutaneous RFA; 3 ) comparator: PEI; 4) results: studies were required to describe data related to at least one of the following primary variables of efficacy and safety, namely, overall survival, local recurrence rate and adverse effects. Other variables such as disease-free survival, complete tumour response and use of health-care resources were considered as secondary outcomes.

Since this study's aim was to identify existing evidence on the efficacy and safety of RFA versus PEI in the treatment of HCC, no limitations based on duration of follow-up period were established [15,17].

\section{Selection of studies}

The selected studies were examined by two independent reviewers, with any disagreements being settled by discussion of the respective study data.

\section{Data extraction}

Original data were extracted on a standard form that included: a) details of the study design, inclusion/exclusion criteria and duration of follow-up; b) information on the study population; $c$ ) information on the intervention and comparator; and lastly, d) information on the outcome measures of efficacy and safety.

\section{Analysis of methodological quality and scientific evidence} This was conducted in accordance with validated recommendations [18].

\section{Data analysis and synthesis of results}

To obtain an overall measure of the efficacy and safety of RFA versus that of the comparator, standard meta-analytical techniques were used. Pooled effect was estimated using a random-effects model [19]. We analysed dichotomous variables using estimation of relative risk (RR) with a 95\% confidence interval, and continuous variables using weighted mean difference (WMD) with a 95\% confidence interval. The degree of inconsistency between studies was quantified using the $\mathrm{I}^{2}$ statistic which describes the proportion of variance across studies not due to chance. $\mathrm{I}^{2}<25 \%$ and $\mathrm{I}^{2}>50 \%$ reflect small and large inconsistency, respectively [20]. Sensitivity analyses were conducted to explore statistical heterogeneity [21].

In accordance with some recent literature we have not used funnel plots to examine the possibility of publication bias, given the limitations and potential misleading results of these graphs [22].

All analyses were performed using the SE Stata 9 computer software package (StataCorp LP Texas USA 1984-2005). Results were deemed significant at a P-value $<0.05$. 
We used Visual RX Version 3 http://www.nntonline.net to calculate, where appropriate, the number needed to treat (NNT) or the number needed to harm (NNH).

\section{Results}

As Figure 1 shows, the bibliographic search yielded 241 references. Hand searching of retrieved articles yielded no additional studies. After excluding references without an abstract, studies with a non percutaneous RFA technical approach, studies not reporting outcomes separately from data on patients with hepatic metastases, and redundancies arising from the use of several databases, a total of seven publications [23-29] were selected.

As Olschewski's [24] data are included within Lencioni et al.'s [25] (Table 1), a total of 6 studies, published from 1999 to 2008 , finally met the inclusion criteria. The studies reported data on 396 patients treated by RFA and 391 treated by PEI. In general, subjects had unresectable HCC without vascular invasion and extrahepatic spread; mean size was $2.5 \mathrm{~cm}$ and $57 \%$ (619 of 1084 tumours) were single tumours. Most patients (74\%) were in Child-Pugh class A (Table 1). Mean duration of follow-up was $25 \pm 11$ months. In every study serial assessments including clini- cal evaluations, analysis of tumour markers and imaging studies were usually performed during follow-up to assess the treatment response and to detect tumour recurrence. Shiina et al. [28] reported that, additionally, when local recurrence was suspected, a biopsy was performed.

As Table 2 shows, there were no significant differences between groups as regards Child-Pugh grade of liver dysfunction, tumour size, number of single tumours and duration of follow-up.

\section{A) Clinical efficacy}

Selected studies report data on overall survival over different time intervals and only in the first 4 years of treatment (Table 1). At 1 year, meta-analysis shows a survival rate of $96 \%$ (95\%CI: $92 \%-98 \%$ ) in the RFA and of $91 \%$ in the PEI treated-group with differences being small but statistically significant in favour of RFA (Table 2). Pooled analyses of the five studies that furnished data on survival at 2 years found an overall survival rate of $86 \%$ (95\%CI:80\%$90 \%)$ in the RFA treated-group $(\mathrm{n}=354)$. Meta-analysis shows, with large consistency across trials, a significant difference in favour of RFA (Table 2) being the calculated NNT of 11 (95\%CI:7-23).

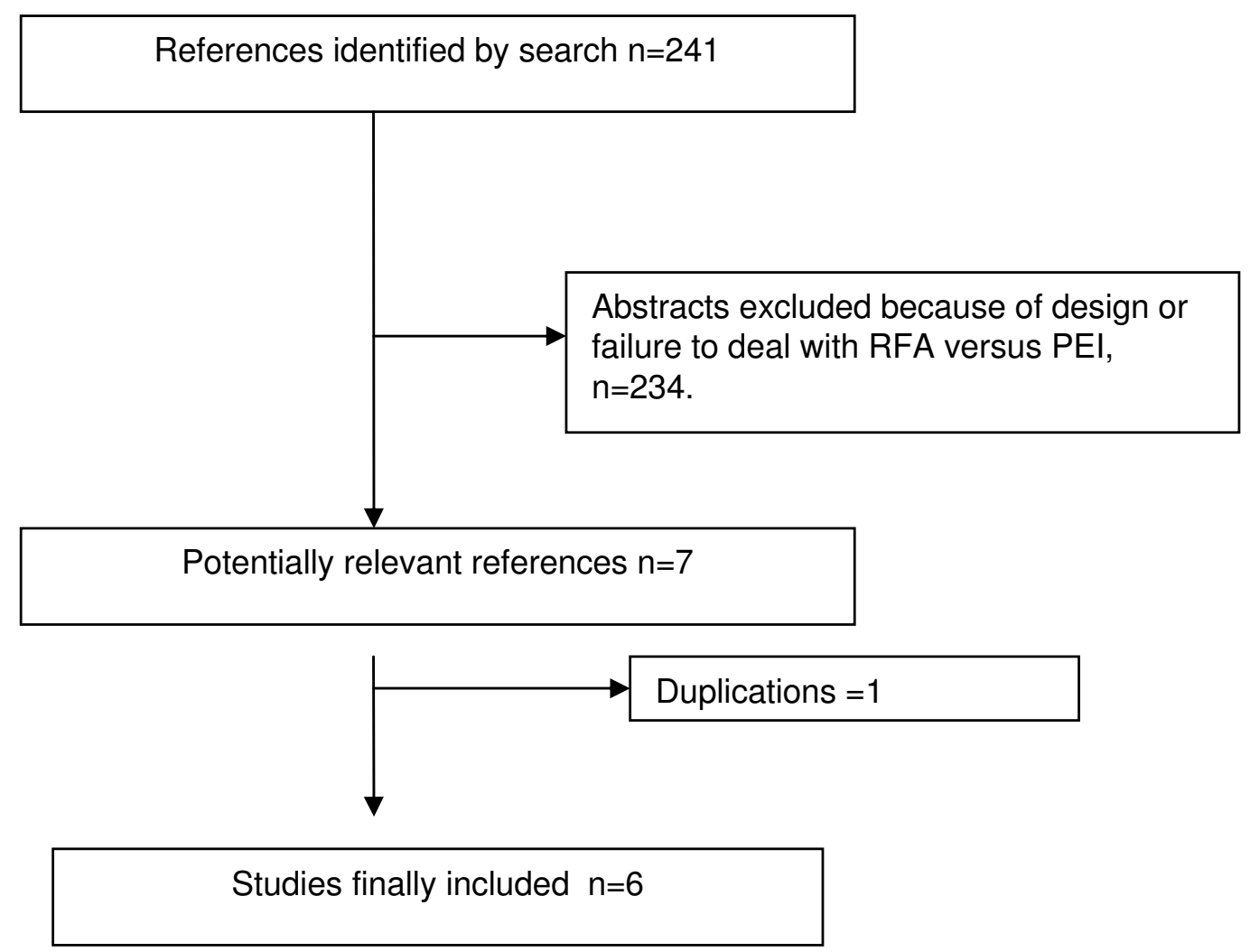

Figure I

Flow diagram for study selection and inclusion. 
Table I: Percutaneous RFA vs. PEI. Summary of characteristics and quality of included studies.

\begin{tabular}{|c|c|c|c|c|c|c|c|}
\hline $\begin{array}{l}\text { Author/year of } \\
\text { publication }\end{array}$ & Design & Inclusion criteria & $\begin{array}{l}\text { RFA } \\
\mathbf{P},[\mathrm{T}]\end{array}$ & $\begin{array}{l}\text { PEI } \\
\text { P, [T] }\end{array}$ & $\begin{array}{l}\text { Child-Pugh } \\
\text { A/B/C }\end{array}$ & $\begin{array}{l}\text { Mean follow-up } \\
\text { (months/years) }\end{array}$ & Quality \\
\hline $\begin{array}{l}\text { Livraghi24 } \\
1999\end{array}$ & quasi-RCT & $\begin{array}{l}\text { Cirrhosis/chronic hepatitis and HCC } \\
\leq 3 \mathrm{~cm} \text {. }\end{array}$ & $42,[52]$ & $44,[60]$ & $\begin{array}{l}\text { RFA } 39 / 3 / 0 \\
\text { PEI } 38 / 6 / 0\end{array}$ & 10 m. (4-28) & 2Diii \\
\hline $\begin{array}{l}\text { Lencioni }{ }^{26} 2003 \\
\text { includes Olschewski25 }\end{array}$ & $\mathrm{RCT}$ & $\begin{array}{l}\text { Cirrhosis, single HCC } \leq 5 \mathrm{~cm} \text { or } 3 \\
\text { nodules } \geq 3 \mathrm{~cm} \text { each. } \mathrm{HCC} \text { at } \mathrm{I} \mathrm{cm} \\
\text { hepatic hilum or gallbladder. No } \\
\text { vascular invasion or extrahepatic } \\
\text { metastasis. Child-Pugh: A or B. No } \\
\text { previous treatment. No candidate } \\
\text { for resection-transplantation. }\end{array}$ & $52,[69]$ & $50,[73]$ & $\begin{array}{l}\text { RFA } 45 / 7 / 0 \\
\text { PEI } 35 / 15 / 0\end{array}$ & $\begin{array}{l}\text { RFA } 22.9 \pm 9.4 \mathrm{~m} \\
\text { PEI } 22.4 \pm 8.6 \mathrm{~m}\end{array}$ & IiiA \\
\hline $\begin{array}{l}\operatorname{Lin} 27 \\
2004\end{array}$ & $\mathrm{RCT}$ & $\begin{array}{l}\text { Cirrhosis, } \mathrm{HCC} \mathrm{I-4} \mathrm{cm} \mathrm{maximum.} \\
\text { Child-Pugh A or B. No previous } \\
\text { treatment. Tumour site }>5 \mathrm{~mm} \text { from } \\
\text { the hilum or common bile duct. }\end{array}$ & $52,[64]$ & $52,[56]$ & $\begin{array}{l}\text { RFA } 4 I / I I / 0 \\
\text { PEI } 39 / 12 / 0\end{array}$ & $\begin{array}{l}\text { RFA } 24.5 \pm 1.3 \mathrm{~m} \\
\text { PEI } 23.8 \pm 10.4 \mathrm{~m}\end{array}$ & IiiA \\
\hline $\begin{array}{l}\operatorname{Lin}^{28} \\
2005\end{array}$ & $\mathrm{RCT}$ & $\begin{array}{l}\mathrm{I}-3 \mathrm{HCC} \leq 3 \mathrm{~cm} \text {, a minimum of I } \\
\mathrm{cm} \text { from the hilum and gallbladder, } \\
\text { no vascular invasion or extrahepatic } \\
\text { metastasis. Child-Pugh A or B } \\
\text { cirrhosis. Initial treatment. }\end{array}$ & $62,[78]$ & $62,[76]$ & $\begin{array}{l}\text { RFA } 46 / 16 / 0 \\
\text { PEI } 47 / 15 / 0\end{array}$ & $\begin{array}{l}\text { RFA } 28 \pm 12 \mathrm{~m} \\
\text { PEI } 26 \pm 13 \mathrm{~m}\end{array}$ & IiiA \\
\hline $\begin{array}{l}\text { Shiina29 } \\
2005\end{array}$ & $\mathrm{RCT}$ & $\begin{array}{l}\text { Unresectable HCC or patient's } \\
\text { refusal of surgery. } \leq 3 \text { lesions } \leq 3 \mathrm{~cm} \text {. } \\
\text { Child-Pugh A or B. No extrahepatic } \\
\text { metastasis or vascular invasion. No } \\
\text { previous or simultaneous } \\
\text { malignancy. }\end{array}$ & I I8, [187] & II4, [192] & $\begin{array}{l}\text { RFA } 85 / 33 / 0 \\
\text { PEI } 85 / 29 / 0\end{array}$ & $\begin{array}{l}\text { RFA } 0.6-4.3 y \text {. } \\
\text { PEI } 0.1-4.2 y\end{array}$ & IiiA \\
\hline $\begin{array}{l}\text { Brunello30 } \\
2008\end{array}$ & $\mathrm{RCT}$ & $\begin{array}{l}\text { Cirrhotic patients in Child-Pugh A or } \\
\mathrm{B} \text { with } \mathrm{I}-3 \mathrm{HCC} \text { nodes } \leq 3 \mathrm{~cm} \text {. } \\
\text { Tumour site } \geq \mathrm{I} \mathrm{cm} \text { from the hilum, } \\
\text { gallbladder, colon or stomach. No } \\
\text { venous invasion, no metastatic } \\
\text { disease. Patients no suitable for } \\
\text { resection or liver transplantation. }\end{array}$ & $70,[89]$ & $69,[88]$ & $\begin{array}{l}\text { RFA } 39 / 31 / 0 \\
\text { PEI } 39 / 30 / 0\end{array}$ & $\begin{array}{l}\text { RFA } 26.1 \mathrm{~m} \text {. } \\
\text { PEI } 25.3 \mathrm{~m} \text {. }\end{array}$ & liiA \\
\hline
\end{tabular}

RCT: randomised controlled trial. RFA: Percutaneous radiofrequency ablation. PEl: Percutaneous ethanol injection; P: patients; T: tumours. Quality of studies: all based on reference 19.

At 3 years, the pooled analysis of the 4 studies furnishing data shows that $74 \%$ (95\%CI: $66 \%-86 \%$ ) of RFA treatedpatients $(\mathrm{n}=302)$ survived. Furthermore, this analysis shows, also with a high degree of consistency, that RFA achieved a significantly higher survival rate than PEI (Table 2, Figure 2) with a calculated NNT of 7 (95\%CI:4-15).

Data from the two studies analysing this variable at 4 years indicate $62 \%$ survival rate (95\% CI: $54 \%-75 \%$ ) in the RFA-treated group. Joint analysis also shows a statistically significant improvement in survival in this group compared to PEI (Table 2). The calculated NNT here is 9 (95\%CI: 5-40).

Furthermore, pooled analysis of studies furnishing data found that, at the end of the follow-up period, the rates of local tumour recurrence were 7\% (95\%CI: 4\%-10\%) and $22 \%(95 \% \mathrm{CI}: 17 \%-27 \%)$ in the RFA and PEI treated- groups respectively. These differences were found to be statistically significant (Figure 3, Table 2), with a calculated NNT of 9 (95\%CI: 6-25).

Concerning secondary outcomes, as Table 2 shows, our results indicate that one, two and three year disease-free survival rates were significantly higher in the RFA group. Likewise RFA was accompanied by a significantly higher rate of radiological complete necrosis. Conversely, no statistical differences were found as regards remote intrahepatic recurrence outside the treated field.

\section{B) Safety}

Table 3 lists the complications reported in individual studies. Overall, complications were described in $19 \%$ of patients (95\% CI: $15 \%-23 \%)$ treated by RFA and in $10.5 \%(95 \%$ CI:7-13.5\%) of those treated by PEI, with the difference 
Table 2: P-RFA vs. PEI: Results of meta-analysis

\begin{tabular}{|c|c|c|c|c|c|}
\hline \multirow[t]{2}{*}{ Variables } & \multirow[t]{2}{*}{ No. of studies furnishing data } & \multicolumn{2}{|c|}{ Results } & \multirow[t]{2}{*}{ RR/WMD (95\% CI) P-value } & \multirow[t]{2}{*}{12} \\
\hline & & RFA & PEI & & \\
\hline \multicolumn{6}{|l|}{ Baseline characteristics: } \\
\hline Child-Pugh grade of liver dysfunction & $6^{24,26-30}$ & $71 \%$ & $70 \%$ & $1.05(0.97,1.13), 0.44$ & $0 \%$ \\
\hline 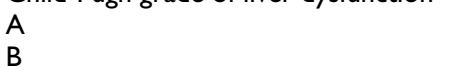 & $624,26-30$ & $24 \%$ & $26 \%$ & $0.92(0.74,1.15), 0.43$ & $0 \%$ \\
\hline Tumour size, $\mathrm{cm}$ (mean \pm SEM) & $4^{26-28,30}$ & $2.62 \pm 0.33$ & $2.47 \pm 0.35$ & $0.13(0.01,0.25), 0.03$ & $0 \%$ \\
\hline Single nodule & $6^{24,26-30}$ & $59 \%$ & $55 \%$ & $1.04(0.94,1.50), 0.44$ & $17 \%$ \\
\hline $\begin{array}{l}\text { Follow-up duration, months } \\
\text { (mean } \pm \text { SEM) }\end{array}$ & $3^{26-28}$ & $25 \pm 6.2$ & $23.6 \pm 5.6$ & $0.97(-1.32,3.3), 0.4$ & $0 \%$ \\
\hline \multicolumn{6}{|l|}{ Efficacy: } \\
\hline Survival & $5^{26-30}$ & $96 \%$ & $91 \%$ & $1.04(1.007,1.08), 0.02$ & $0 \%$ \\
\hline I year & $526-30$ & $86 \%$ & $75 \%$ & $1.13(1.06,1.20),<0.001$ & $0 \%$ \\
\hline 2 years & $427-30$ & $73 \%$ & $58 \%$ & $1.28(1.12,1.45),<0.001$ & $12.6 \%$ \\
\hline 3 years & $2^{29,30}$ & $62 \%$ & $51 \%$ & $1.24(1.05,1.48),<0.001$ & $0 \%$ \\
\hline \multicolumn{6}{|l|}{4 years } \\
\hline Local recurrence & $426-29$ & $7 \%$ & $22 \%$ & $0.37(0.23,0.59), 0.000$ & $0 \%$ \\
\hline Disease-free survival & $3^{26-28}$ & $80 \%$ & $70 \%$ & I.I $3(I, 1.28), 0.04$ & $0 \%$ \\
\hline I year & $3^{26-28}$ & $61 \%$ & $42 \%$ & $1.31(1.06,1.61), 0.013$ & $0 \%$ \\
\hline 2 years & $2^{27,28}$ & $40 \%$ & $19 \%$ & $2.1(1.35,3.23), 0.001$ & $0 \%$ \\
\hline 3 years & & & & & \\
\hline Tumour complete response & $4^{24,26-28}$ & $93.5 \%$ & $84.5 \%$ & $1.10(1.04,1.17), 0.01$ & $0 \%$ \\
\hline Remote intra-hepatic recurrence & $5^{26-30}$ & $43 \%$ & $45 \%$ & $0.97(0.82,1.11), 0.56$ & $0 \%$ \\
\hline \multicolumn{6}{|l|}{ Safety: } \\
\hline Total complications & $624,26-30$ & $19.2 \%$ & $10.5 \%$ & $2.55(1.8,3.65),<0.001$ & $0 \%$ \\
\hline Major complications & $424,28-30$ & $4.1 \%$ & $2.7 \%$ & $1.85(0.68,5.01) ; 0.22$ & $0 \%$ \\
\hline
\end{tabular}

RR: Relative risk. WMD: Weighted mean difference. All based on random effects meta-analysis.

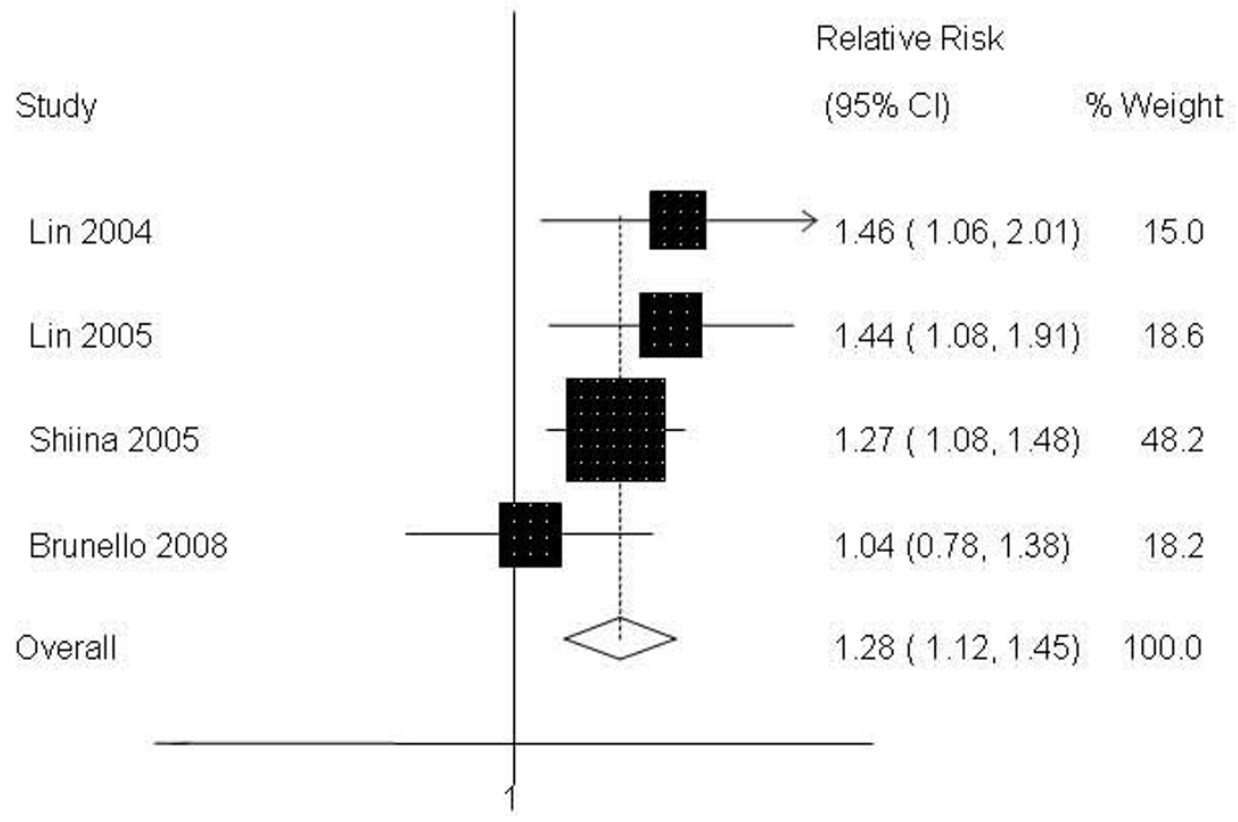

Figure 2

RFA vs. PEI: Results of the meta-analysis on overall survival at 3 years. Cl: Confidence interval. All based on a random-effects meta-analysis. 


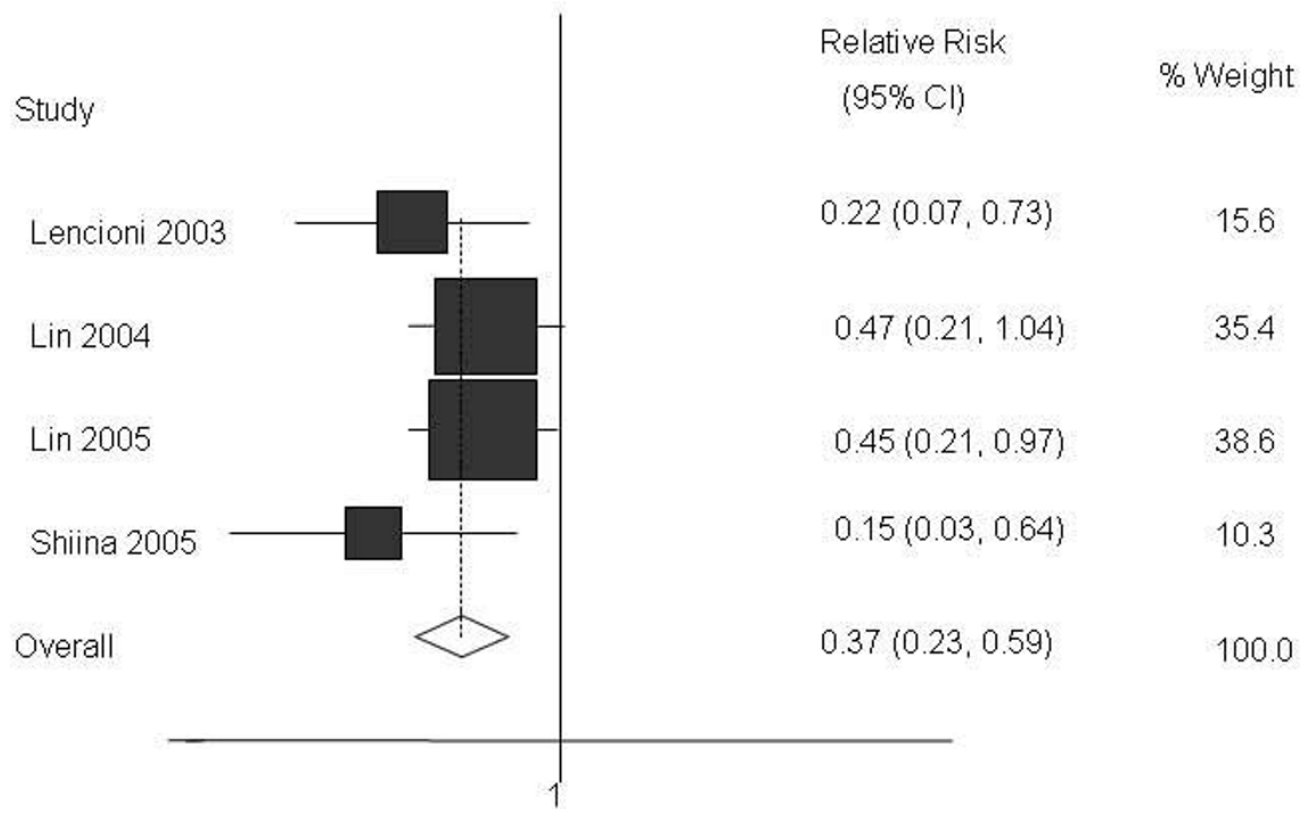

Figure 3

RFA vs. PEI: Results of the meta-analysis on local recurrence rate. $\mathrm{Cl}$ : Confidence interval. All based on a randomeffects meta-analysis.

Table 3: RFA vs. PEI. Summary of complications described in individual studies

\begin{tabular}{|c|c|c|}
\hline Type & RFA (number of cases) & PEI (number of cases) \\
\hline Severe pain & 27 & 14 \\
\hline Fever & 10 & 5 \\
\hline Haemothorax & 4 & \\
\hline Pneumothorax & I & \\
\hline Pleural effusion & 7 & \\
\hline Gastric perforation & I & \\
\hline Cholecystitis & 1 & \\
\hline Intraperitoneal bleeding & 2 & I \\
\hline Haemobilia & 1 & \\
\hline Hepatic infarction & 1 & \\
\hline Subcapsular haematoma & 5 & 1 \\
\hline Transitory icterus & I & \\
\hline Ascitis & 1 & 2 \\
\hline Acute cholangitis & & I \\
\hline Hepatic abscess & & I \\
\hline Portal vein thrombosis & 2 & 9 \\
\hline Biliary stricture & 1 & \\
\hline Hypertransaminaemia & 3 & 1 \\
\hline Thermal burn to colon & 1 & \\
\hline Cutaneous burn & I & 2 \\
\hline$A-V$ shunt & 3 & \\
\hline Neoplastic cell seeding & 3 & 1 \\
\hline Psychotic reaction & & I \\
\hline Vagal reaction & & 1 \\
\hline Procedure-related death & & I \\
\hline
\end{tabular}


being statistically significant and favourable to PEI (Table 2) and an estimated NNH of 7 (95\%CI:4-13) with RFA.

Only four studies report on complications defined as being major by the respective authors. The rate of major complications in the RFA treated-patients was $4.1 \%$ (95\%CI: $1.8 \%-6.4 \%$ ) and include: haemotorax requiring thoracostomy drainage, gastric bleed, haemoperitoneum, transitory icterus, liver infarction, cutaneous burn and tumoral cell seeding. In the PEI-group, 2.7\% (95\%CI: $0.4 \%-5.1 \%$ ) of patients had major complications including: liver abscess, haemoperitoneum, tumoral cell seeding and one procedure-related death. Pooled analysis of these major complications, showed that, despite there being a trend towards a greater number in the RFA group, this difference failed to reach statistical significance (Table 2).

\section{C) Use of resources}

Joint analysis of four studies [25-28] indicates that the number of sessions per tumour treated was significantly lower in the case of RFA (WMD: -4.26, $(-4.8,-3.7)$, $\left.<0.001 ; \mathrm{I}^{2}: 88 \%\right)$. When potential reasons for heterogeneity were explored, the studies varied in terms of both clinical variables and methodological quality. However, a range of sensitivity analysis showed no appreciable differences between the pooled-effect sizes obtained.

Three studies [26-28] furnished combinable data on mean hospital stay. In two of these, hospital stay was longer in the RFA-treated group, whilst Shiina et al. report data on very prolonged stays in the PEI-treated group, without citing the causes. Although combined analysis showed no significant differences [WMD: -2.91 (-7.91, 2.08), $\mathrm{P}=0.2]$, inconsistency across studies was very pronounced ( $\left.\mathrm{I}^{2}: 99 \%\right)$, rendering interpretation of results difficult.

Only Brunello et al. [29] conducted a formal evaluation of hospital costs. These authors found that the mean direct medical costs were 4097 for patients in the PEI group and 6540 for those in the RFA group $(\mathrm{p}<0.001)$. In addition, they estimated an incremental health-care cost of 8286 (95\%CI: 2742-20 917 ) for each additional patient successfully treated by RFA.

\section{Discussion}

The results of this meta-analysis indicate that RFA is superior to PEI in terms of overall survival and lower local recurrence rates for patients with Child-Pugh class A or B cirrhosis and an early nonsurgical HCC. However, the higher rate of adverse events displayed is something that will have to be tested with appropriate weighting of the possible benefits in each individual case.

While according to recent guidelines PEI should be considered the standard technique for percutaneous treatment of HCC in patients with cirrhosis [30], RFA has emerged as a real competitor to PEI in clinical grounds and is currently used as the primary ablative modality at most institutions [31,32]. However, to date, the survival benefit of RFA versus that of PEI for HCC is controversial $[1,13,14,31]$.

In this study, a significant benefit in RFA vs. PEI in overall survival was observed. Interestingly enough, though individual studies provide data only in the first 4 years of treatment, the advantage in survival increases with time. Indeed at 3 years there is a $28 \%$ higher survival rate for the RFA-treated group with a calculated NNT of 7 . From a clinical point of view these findings seem to be highly significant, and although the number of studies furnishing combinable data is limited, the absence of patent differences between groups with regards to Child-Pugh grade of liver dysfunction, tumour size or number of single tumours, highlights the possible benefits of RFA itself. Furthermore it is important to emphasize the high degree of consistency found across studies and their methodological quality, something that increases the strength of these results. In addition, the rates of survival found in the PEI group, while somewhat lower, are comparable to that reported in prior studies conducted in patients with HCC of similar characteristics $[33,34]$.

The improvement observed regarding survival can be explained by the fact that, as this study confirms, RFA is superior to PEI in achieving local control of the disease as demonstrated by its greater disease-free survival rates, complete radiological tumour response, and its significantly lower local recurrence rates [31,35-38]. Concerning this cardinal variable, our data show, with enormous consistency across the combinable studies, that RFA has a $63 \%$ lesser risk of local recurrence than PEI with a calculated NNT of 9 (95\%CI: 6-25). Conversely, and as expected because it is not influenced by local treatment, no significant differences were found concerning remote hepatic recurrence rates outside the treated field [38].

Insofar as safety is concerned, though data are limited, available evidence indicate that, whereas there are no significant differences between the two techniques in the case of major complications, RFA displays an overall complication rate which is significantly higher than that observed with PEI, with a calculated NNH of about 7.

The overall rate of complications was $19 \%$ in the RFA treated-group, which is clearly higher than the $7 \%$ previously reported for this percutaneous approach [39]. On the other hand, we should point out that the rate of major complications found in this study (4\%) is rather comparable to recently published data [40]. While these rates do not translate into an increase in mortality they have to be taken into account, especially because this procedure has rapidly evolved into the most popular percutaneous ther- 
apy for HCC in clinical settings. Here, we must point out that some of the complications observed could be due to the effect of the learning curve [41] and professionals' differing degree of experience [42] in RFA.

Lastly, RFA seems superior to PEI in terms of some healthresource-related variables, such as number of sessions per tumour treated and mean hospital stay. In contrast, in the cost-effectiveness analysis made by Brunello et al. [29], RFA was found to be more expensive than PEI with mean direct costs showing a significant positive difference not balanced by a better impact on the overall survival rate. Consequently, to date there is no evidence supporting a better cost-effectiveness ratio for RFA from a social perspective. In addition, it is important to recognise the difficulties in comparing the length of hospital stay and the costs of RFA versus PEI among studies of diverse setting due, in part, to the difference in resource use and patterns of care between different countries. These differences also hinder direct comparisons and extrapolation of the results to different communities.

\section{Potential report limitations}

It has to be recognised that publication bias is possible and that, by not including unpublished studies, the efficacy and safety of RFA versus PEI may not have been fully adequately estimated. Nevertheless, we feel that any such bias would necessarily have been minimised by the scope of and systematic strategy used in the search of the literature and we are confident that the majority of the research conducted in this field was successfully identified $[15,43]$. However, in line with prior reports, we decided not to include unpublished data from industry given both the difficulties encountered in obtaining this information and the recognition that the use of these data may not necessarily reduce the bias in meta-analysis $[43,44]$.

We should, moreover, stress the fact that, in this study, a number of accredited methods were used to reduce possible biases (extensive search of the literature; duplicate data-extraction; use of explicit criteria for both methodological assessment and analysis; and use of a randomeffects model for effect estimation). Additionally, cardinal clinical results as overall survival were analysed [45].

Lastly, this study highlights the presence of several limitations in the papers located in the literature among which the cursory description of results and the absence of stratification according to recognised prognostic parameters with regards to both tumour size and hepatic functional reserve, reduce the possibility of the applications and clinical limitations of RFA being identified more accurately. In this regard, it has to be recognised that although the efficacy of RFA is known to be size dependent [36], no subgroup analysis based on tumour size could be carried out given the absence of adequate information on this respect in the individual studies. Similarly, there is an evident lack of long-term data on patient survival. Most of the studies had follow-up periods of approximately 2-3 years and there are no consistent data on longer followups. There is no doubt that this is a limitation which will be overcome in the future, rendering it possible for patient prognoses to be correctly evaluated.

\section{Conclusion}

Despite limitations, available evidence from adequate quality controlled studies support the superiority of RFA versus PEI in terms of better survival and local control of the disease for the treatment of patients with relatively preserved liver function and early-stage non-surgical HCC. However, the higher rate of adverse events displayed is something that will have to be tested with appropriate weighting of the possible benefits in each individual case. Overall cost-effectiveness of RFA needs further evaluation.

\section{Competing interests}

The authors declare that they have no competing interests.

\section{Authors' contributions}

CB participated in the design and coordination of the study, carried out the critical appraisal of studies and wrote the manuscript. RA, ZSP and TLC developed the literature search, carried out the extraction of data, assisted in the critical appraisal of included studies and assisted in writing up. CB and TLC carried out the statistical analysis of studies. JMA coordinated the project (SEC 2001-0138) and assisted in writing up. All authors read and approved the final manuscript.

\section{Acknowledgements}

This study was commissioned by the Health Technology Assessment Programme on behalf of the Ministry of Health \& Consumer Affairs and was partially funded by the Spanish National I+D Program Ministry of Science \& Technology (to C Bouza, Z Saz and JM Amate, grant SEC 200I-0I38 and

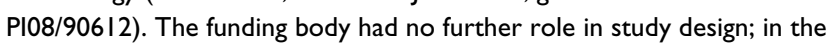
collection, analysis and interpretation of data; in the writing of the report; and in the decision to submit the paper for publication.

\section{References}

I. Llovet JM: Updated treatment approach to hepatocellular carcinoma. J Gastroenterol 2005, 40:225-235.

2. Parkin DM, Bray F, Ferlay J, Pisani P: Global cancer statistics, 2002. CA Cancer J Clin 2005, 55:74- 108.

3. El-Serag HB, Mason AC: Rising incidence of hepatocellular carcinoma in the United States. N Engl J Med 1999, 340:745-750.

4. Bosch FX, Ribes J, Diaz M, Cleries R: Primary liver cancer: worldwide incidence and trends. Gastroenterology 2004, I 27:S5-I6.

5. Llovet JM, Bustamante J, Castells A, Vilana R, Ayuso Mdel C, Sala M, Brú C, Rodés J, Bruix J: Natural history of untreated nonsurgical hepatocellular carcinoma: Rationale for the design and evaluation of therapeutic trials. Hepatology 1999, 29:62-67.

6. Arguedas MR, Chen VK, Eloubeidi MA, Fallon MB: Screening for hepatocellular carcinoma in patients with hepatitis $\mathbf{C}$ cirrhosis: a cost-utility analysis. Am J Gastroenterol 2003, 98:679-690.

7. Llovet JM, Beaugrand M: Hepatocellular carcinoma: present status and future prospects. J Hepatol 2003, 38:SI36-49. 
8. Bruix J, Llovet JM: Locoregional treatments for hepatocellular carcinoma. Baillière Clin Gastroenterol 1999, 13:6 | I-622.

9. Erce C, Parks RW: Interstitial ablative techniques for hepatic tumours. Br J Surg 2003, 90:272-289.

10. Bilchik AJ, Rose DM, Allegra DP, Bostick PJ, Hsueh E, Morton DL: Radiofrequency ablation: a minimally invasive technique with multiple applications. Cancer J Sci Am 1999, 5:356-36I.

1I. Goldberg SN: Radiofrequency tumour ablation: principles and techniques. Eur J Ultrasound 200I, 13:|29-|47.

12. Galandi D, Antes G: Radiofrequency thermal ablation versus other interventions for hepatocellular carcinoma (Cochrane Review). In The Cochrane Library Issue 3 Oxford: Update Software; 2003.

13. Lopez PM, Villanueva A, Llovet JM: Systematic review: evidencebased management of hepatocellular carcinoma-an updated analysis of randomized controlled trials. Aliment Pharmacol Ther 2006, 23:1535-1547.

14. Sutherland LM, Williams JA, Padbury RT, Gotley DC, Stokes B, Maddern G]: Radiofrequency ablation of liver tumours: a systematic review. Arch Surg 2006, I4I: I8I-190.

15. Royle $\mathrm{P}$, Waugh $\mathrm{N}$ : Literature searching for clinical and costeffectiveness studies used in health technology assessments reports carried out for the National Institute for Clinical Excellence appraisal system. Health Technol Assess 2003, 7(34): iii, ix $-x,|-5|$

16. Sackett DL, Richardson WS, Rosenberg W, Hayes RB: Evidence-Based Medicine. How to Practice and Teach EBM New York: Churchill Livingstone; 1997.

17. Hartling L, Mcalister FA, Rowe BH, Ezekowitz J, Friesen C, Klassen TP: Challenges in Systematic Reviews of Therapeutic Devices and Procedures. Ann Intern Med 2005, I 42: I 100-I I I I.

18. National Cancer Institute. Classification of Evidence [http:// www.cancer.gov]

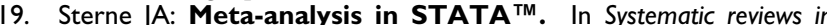
Health Care: Meta-Analysis in Context 2nd edition. Edited by: Egger M, Davey Smith G, Altman DG. BMJ books. London: Blackwell Publishing; 200I:347-369.

20. Higgins JPT, Thompson SG, Deek JJ, Altman DG: Measuring inconsistency in metaanalyses. Br Med J 2003, 327:557-560.

21. Higgins J, Thompson S, Deeks J, Altman D: Statistical heterogeneity in systematic reviews of clinical trials: a critical appraisal of guidelines and practice. J Health Serv Res Policy 2002, 7:5 I-61.

22. Tang J, Liu JL: Misleading funnel plot for detection of bias in meta-analysis. J Clin Epidemiol 2000, 53:477-484.

23. Livraghi T, Goldberg SN, Lazzaroni S, Meloni F, Solbiati L, Gazelle GS: Small hepatocellular carcinoma: treatment with radio-frequency ablation versus ethanol injection. Radiology 1999 , 2 | 0:655-66l.

24. Olschewski M, Lencioni R, Allgaier HP, Cioni D, Deibert P, Frings H: $A$ randomised comparison of radiofrequency thermal ablation and percutaneous ethanol injection for the treatment of small hepatocellular carcinoma [abstract]. Proc Am Soc Clin Oncol 2001:500.

25. Lencioni RA, Allgaier HP, Cioni D, Olschewski M, Deibert P, Crocetti L, Frings H, Laubenberger J, Zuber I, Blum HE, Bartolozzi C: Smal hepatocellular carcinoma in cirrhosis: randomized comparison of radio-frequency thermal ablation versus percutaneous ethanol injection. Radiology 2003, 228:235-240.

26. Lin SM, Lin CJ, Lin CC, Hsu CW, Chen YC: Radiofrequency ablation improves prognosis compared with ethanol injection for hepatocellular carcinoma $<$ or $=\mathbf{4} \mathbf{~ c m}$. Gastroenterology 2004, 127:17|4-1723.

27. Lin SM, Lin CJ, Lin CC, Hsu CW, Chen YC: Randomised controlled trial comparing percutaneous radiofrequency thermal ablation, percutaneous ethanol injection, and percutaneous acetic acid injection to treat hepatocellular carcinoma of 3 cm or less. Gut 2005, 54:1I5I-II 56.

28. Shiina S, Teratani T, Obi S, Sato S, Tateishi R, Fujishima T, Ishikawa T, Koike Y, Yoshida H, Kawabe T, Omata M: A randomized controlled trial of radiofrequency ablation with ethanol injection for small hepatocellular carcinoma. Gastroenterology 2005, 129:122-130.

29. Bruix J, Sherman M, Llovet JM, Beaugrand M, Lencioni R, Burroughs AK, Christensen E, Pagliaro L, Colombo M, Rodés J, EASL Panel of Experts on HCC: Clinical management of hepatocellular carcinoma. Conclusions of the Barcelona-2000 EASL confer- ence. European Association for the Study of the Liver. Hepatol 200I, 35:42I-430.

30. Brunello F, Veltri A, Carucci P, Pagano E, Ciccone G, Moretto P, Sacchetto $P$, Gandini G, Rizzetto M: Radiofrequency ablation versus ethanol injection for early hepatocellular carcinoma: A randomized controlled trial. Scand J Gastroenterol 2008, 43:727-735.

31. Croccetti L, Lencioni R: Thermal ablation of hepatocellular carcinoma. Cancer Imaging 2008, 27:19-26.

32. Llovet JM, Bruix J: Novel advancements in the management of hepatocellular carcinoma in 2008. J Hepatol 2008, 48(Suppl I):20-37.

33. Lencioni R, Pinto F, Armillotta N, Bassi AM, Moretti M, Di Giulio M, Marchi S, Uliana M, Della Capanna S, Lencioni M, Bartolozzi C: Longterm results of percutaneous ethanol injection therapy for hepatocellular carcinoma in cirrhosis: a European experience. Eur Radiol 1997, 7:5 I4-519.

34. Ebara M, Okabe S, Kita K, Sugiura N, Fukuda H, Yoshikawa M, Kondo $\mathrm{F}$, Saisho H: Percutaneous ethanol injection for small hepatocellular carcinoma: therapeutic efficacy based on 20-year observation. J Hepatol 2005, 43:458-464.

35. Takahashi S, Kudo M, Chung H, Inoue T, Ishikawa E, Kitai S, Tatsumi C, Ueda T, Minami Y, Ueshima K, Haji S: Initial treatment response is essential to improve survival in patients with hepatocellular carcinoma who underwent curative radiofrequency ablation therapy. Oncology 2007, 72(Suppl I):98-103.

36. Livraghi T, Meloni F, Di Stasi M, Rolle E, Solbiati L, Tinelli C, Rossi S: Sustained complete response and complications rates after radiofrequency ablation of very early hepatocellular carcinoma in cirrhosis: Is resection still the treatment of choice? Hepatology 2008, 47:82-99.

37. $\mathrm{Ng} \mathrm{KK}$, Poon RT, Lo CM, Yuen J, Tso WK, Fan ST: Analysis of recurrence pattern and its influence on survival outcome after radiofrequency ablation of hepatocellular carcinoma. J Gastrointest Surg. 2008, I 2(I):|93-19|.

38. Sherman M: Recurrence of hepatocellular carcinoma. N EnglJ Med 2008, 359:2045-2047.

39. Mulier S, Mulier P, Ni Y, Miao Y, Dupas B, Marchal G, De Wever I, Michel $L$ : Complications of radiofrequency coagulation of liver tumours. Br J Surg 2002, 89: I206-I222.

40. Zavaglia C, Corso R, Rampoldi A, Vinci M, Belli LS, Vangeli M, Solcia M, Castoldi C, Prisco C, Vanzulli A, Pinzello G: Is percutaneous radiofrequency thermal ablation of hepatocellular carcinoma a safe procedure? Eur J Gastroenterol Hepatol 2008, 20:196-20|

4I. Poon RT, Ng KK, Lam CM, Ai V, Yuen J, Fan ST, Wong J: Learning curve for radiofrequency ablation of liver tumours. Ann Surg 2004, 239:44I-449.

42. Hildebrand P, Leibecke T, Kleemann M, Mirow L, Birth M, Brusch HP, Bürk $C$ : Influence of operator experience in radiofrequency ablation of malignant liver tumours on treatment outcome. Eur J Surg Oncol 2006, 32:430-434.

43. Song F, Eastwood AJ, Gibody S, Duley L, Sutton AJ: Publication and related biases. Health Technol Assess 2000, 4: I-105.

44. Ferguson D, Laupacis A, Salmi LR, McAlister FA, Huet C: What should be included in meta-analysis?. An exploration of methodological issues. Int J Technol Assess Health Care 2000, 16: I 109-III9.

45. Llovet JM, Di Bisceglie AM, Bruix J, Kramer BS, Lencioni R, Zhu AX, Sherman M, Schwartz M, Lotze M, Talwalkar J, Gores G], Panel of Experts in HCC-Design Clinical Trials: Design and endpoints of clinical trials in hepatocellular carcinoma. I Natl Cancer Inst 2008, 100:698-7II.

\section{Pre-publication history}

The pre-publication history for this paper can be accessed here:

\section{http://www.biomedcentral.com/1471-230X/9/31/pre} pub 